\title{
EVALUATION OF FACTORS ASSOCIATED WITH MORTALITY DURING 7 YEARS AFTER STROKE
}

slimnica

Guna Bērziña, MD, PhD and Illa Mihejeva, MD.

From the Riga Stradiņš University, Department of Rehabilitation and Riga East

University Hospita, Department of Rehabilitation, Riga, Latvia

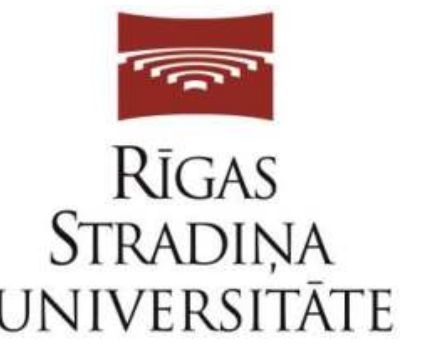

\section{INTRODUCTION}

It is important to explore factors and their interaction to implement more focused stroke care and therefore improve the short- and long-term outcomes, including survival.

\section{PURPOSE}

The aim of this study was to evaluate how prestroke risk factors, neurological symptoms and the level of disability shortly after stroke are associated with post stroke mortality during 7 years after stroke for persons that have been treated in the stoke unit.

\section{METHODS}

The data of 231 patients who were treated in the Stroke unit at the Riga East University Hospital between February 1 and July 20, 2009 were included in the study. Prestroke risk factors, neurological symptoms and limitations of activities early after stroke were used as independent variables in the stepwise Cox proportional hazard analysis to analyse the mortality during 7 years following stroke.

\section{RESULTS}

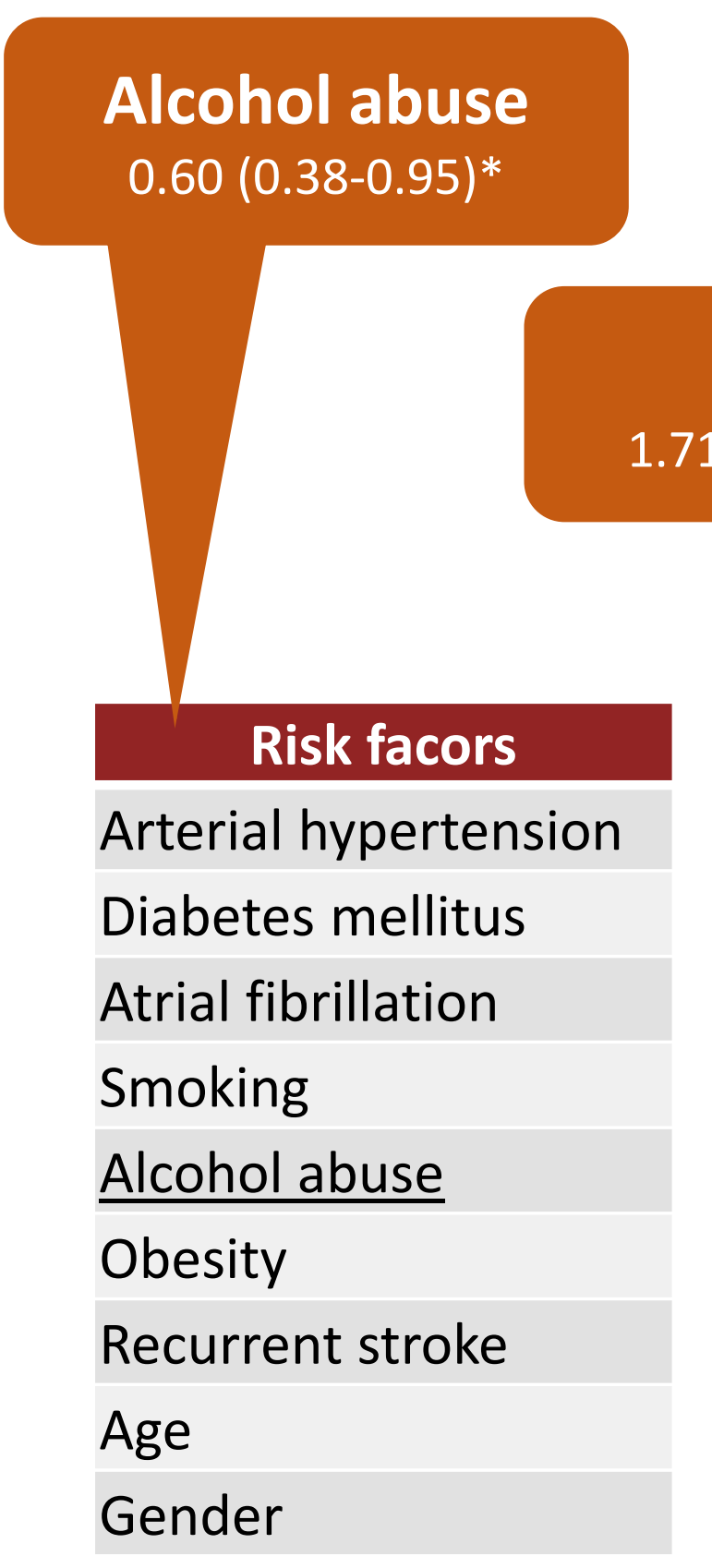

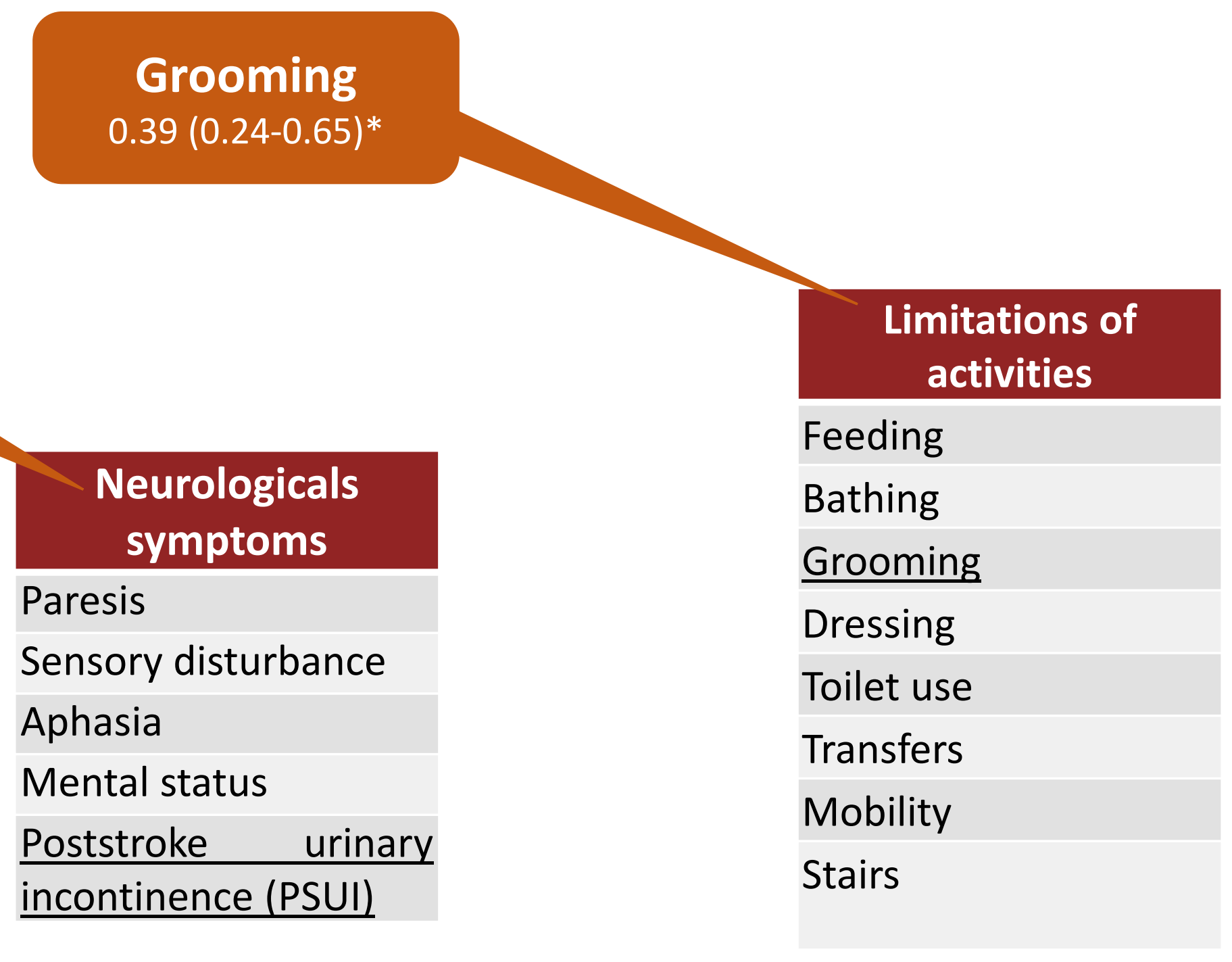

\section{CONCLUSIONS}

Alcohol abuse as a prestroke risk factor, post stroke urinary incontinence as a neurological symptom and dependence in grooming as a factor of disability were associated with earlier mortality during seven years after stroke. 